OPEN ACCESS

Edited by:

Nikolaus Marx,

Uniklinik RWTH Aachen, Germany

Reviewed by:

Andreas Schäfer,

Hannover Medical School, Germany

Christoph Eugen Hagemeyer,

Monash University, Australia

*Correspondence:

Ramzi A. Ajjan

r.ajjan@leeds.ac.uk

Specialty section:

This article was submitted

to Atherosclerosis and

Vascular Medicine,

a section of the journal

Frontiers in Cardiovascular Medicine

Received: 31 October 2017

Accepted: 03 January 2018

Published: 19 January 2018

Citation:

Pechlivani N and Ajjan RA (2018)

Thrombosis and Vascular

Inflammation in Diabetes:

Mechanisms and Potential

Therapeutic Targets.

Front. Cardiovasc. Med. 5:1.

doi: 10.3389/fcrm.2018.00001

\section{Thrombosis and Vascular Inflammation in Diabetes: Mechanisms and Potential Therapeutic Targets}

\author{
Nikoletta Pechlivani and Ramzi A. Ajjan* \\ School of Medicine, Leeds Institute for Cardiovascular and Metabolic Medicine, University of Leeds, Leeds, United Kingdom
}

Cardiovascular disease remains the main cause of morbidity and mortality in patients with diabetes. The risk of vascular ischemia is increased in this population and outcome following an event is inferior compared to individuals with normal glucose metabolism. The reasons for the adverse vascular profile in diabetes are related to a combination of more extensive atherosclerotic disease coupled with an enhanced thrombotic environment. Long-term measures to halt the accelerated atherosclerotic process in diabetes have only partially addressed vascular pathology, while long-term antithrombotic management remains largely similar to individuals without diabetes. We address in this review the pathophysiological mechanisms responsible for atherosclerosis with special emphasis on diabetes-related pathways. We also cover the enhanced thrombotic milieu, characterized by increased platelet activation, raised activity of procoagulant proteins together with compromised function of the fibrinolytic system. Potential new therapeutic targets to reduce the risk of atherothrombosis in diabetes are explored, including alternative use of existing therapies. Special emphasis is placed on diabetes-specific therapeutic targets that have the potential to reduce vascular risk while keeping an acceptable clinical side effect profile. It is now generally acknowledged that diabetes is not a single clinical entity but a continuum of various stages of the condition with each having a different vascular risk. Therefore, we propose that future therapies aiming to reduce vascular risk in diabetes require a stratified approach with each group having a "stage-specific" vascular management strategy. This "individualized care" in diabetes may prove to be essential to improve vascular outcome in this high risk population.

Keywords: atherosclerosis, diabetes mellitus, thrombosis, endothelial dysfunction, vascular inflammation

\section{INTRODUCTION}

The prevalence of diabetes continues to increase and is reaching epidemic proportions. ${ }^{1}$ The vast majority of these patients have type 2 diabetes characterized early in the disease process by insulin resistance (IR) followed by pancreatic $\beta$-cell failure leading to elevated blood glucose and emergence of diabetes (1-3). A minority have type 1 diabetes, secondary to immune destruction of the $\beta$-cells.

${ }^{1}$ http://www.who.int. 
However, these individuals can also develop IR leading to double diabetes, which has features of both type 1 and type 2 diabetes (4), and this group appears to have an enhanced vascular risk.

Despite advances in therapy, cardiovascular disease (CVD) remains the main cause of morbidity and mortality in diabetes $(5,6)$. Similarly to CVD in individuals without diabetes, an increased inflammatory response and an enhanced thrombotic milieu represent the two main pathological pathways underpinning atherothrombosis in diabetes. However, the adverse vascular process is accelerated in diabetes, secondary to a combination of IR and elevated blood glucose levels. Understanding the exact mechanisms involved in disease initiation and progression is crucial in order to develop effective vascular preventative and therapeutic treatment strategies (7-9).

This review summarizes the pathophysiological mechanisms responsible for increased atherothrombotic risk in diabetes, addresses current treatment modalities, and explores additional pathways that can be targeted to reduce vascular events in this high-risk population.

\section{Pathophysiology}

Both extensive vascular pathology and an enhanced thrombotic environment contribute to premature vascular occlusive events and poor clinical outcome in patients with diabetes.

A normal endothelial cell (EC) function is the key to maintain vascular health. EC dysfunction is one of the earliest abnormalities in the atherothrombotic process, which also contributes to the latter stages of the disease. Another central mechanism in vascular pathology is systemic inflammation, which promotes vascular damage. EC dysfunction and an inflammatory milieu are both associated with a prothrombotic and hypofibrinolytic environment, facilitating vascular occlusion and leading to myocardial infarction, stroke, and occlusive peripheral vascular disease, common complications in patients with diabetes.

\section{EC Dysfunction}

The endothelium plays an important role in maintaining vascular homeostasis by regulating vasodilation and vasoconstriction, thrombosis and fibrinolysis, platelet activation, platelet and leukocyte interaction, and smooth muscle cell function. Under physiological conditions, the endothelium modulates vascular tone by producing and releasing various vasodilator substances, most importantly nitric oxide (NO), and vasoconstrictor substances including endothelin $(10,11)$. When EC dysfunction occurs, secondary to IR with or without elevated blood glucose levels, vascular homeostasis is disturbed and the process of atherosclerosis ensues $(11,12)$. EC dysfunction results in these cells expressing adhesion molecules, thus attracting inflammatory cells. Moreover, EC dysfunction disrupts the barrier function of these cells causing the movement of low-density lipoprotein cholesterol (LDL) from vessel lumen into the wall, where it is oxidized to the highly atherogenic ox-LDL. This molecule is then taken up by inflammatory cells that moved from the blood stream to the vessel wall secondary to increased permeability of dysfunctional EC. The uptake of ox-LDL by macrophages results in the formation of foam cells, which aggregate together to form the fatty streak, the earliest abnormality in the atherosclerotic process, and which can be found as early as childhood. An inflammatory reaction is followed by deposition of collagen, gradually transforming the healthy vessel wall into a series of atherosclerotic plaques. Once the atherosclerotic plaque ruptures, it exposes a prothrombotic core resulting in activation of platelets and the protein phase of coagulation, culminating in the formation of the obstructive vascular clot.

Endothelial cell dysfunction plays a role in all stages of the atherosclerotic process from initiation of atherosclerosis to precipitation of thrombosis $(10,13)$, as summarized in Figure 1. Therefore, therapy targeted at improving the health of these cells would help to reduce the risk of atherothrombosis. In diabetes, this includes general measures, such as ensuring good glycemic control, reducing IR, and optimizing blood pressure control. However, there are additional steps that can be undertaken to target specific pathways, which are further detailed below.

\section{Vascular Inflammation and Atherosclerosis in Diabetes}

We will concentrate on diabetes-specific pathways for vascular pathology related to IR and elevated glucose levels.

Reduced NO bioavailability and elevated levels of reactive oxygen species (ROS) play fundamental roles in vascular disease in diabetes (Figure 1). IR inhibits NO production by decreasing the activity of endothelial NO synthase (eNOS) resulting in reduced vasodilation (14-16). In addition to reduced production of vasodilators, there is an increased production of vasoconstrictors in diabetes. For example, the vasoconstrictor endothelin-1 is involved with endothelial dysfunction and increased plasma levels have been associated with microangiopathy in type 2 diabetes (17). Furthermore, increased arterial stiffness in diabetes has been associated with phenotype switching of vascular smooth muscle cells, a process that appears to be controlled by microRNAs (miRNAs); miR-145 has recently been shown to modulate the phenotypic switch of vascular smooth muscle cells from a contractile to a proliferative state in atherosclerosis $(18,19)$.

Decreased NO bioavailability has also been related to platelet activation. An in vivo study in diabetic mice has demonstrated that inhibiting NO synthase reduced platelet vasodilator-stimulated phosphoprotein (VASP) phosphorylation and increased fibrinogen-platelet binding and expression of P-selectin as well as CD40 ligand. Diabetic mice also exhibited reduced VASP phosphorylation, increased fibrinogen-platelet binding, and enhanced expression of P-selectin/CD40 ligand, which was rescued by endothelial-specific restoration of $\mathrm{NO}$ production (20). This emphasizes the importance of NO production by ECs in controlling platelet activation, a process that is compromised in the presence of endothelial dysfunction.

Hyperglycemia in diabetes and elevated levels of free fatty acids enhance ROS production, which in turn compromises NO synthesis via a number of cellular mechanisms. More specifically, free fatty acids bind to Toll-like receptor, activating NF- $\kappa \mathrm{B}$, which stimulates inflammation by increasing the expression of the inflammatory molecules interleukin (IL)- 6 and tumor necrosis factor (TNF)- $\alpha$. Moreover, the stimulation of the tolllike receptor induces the phosphorylation of insulin receptor 


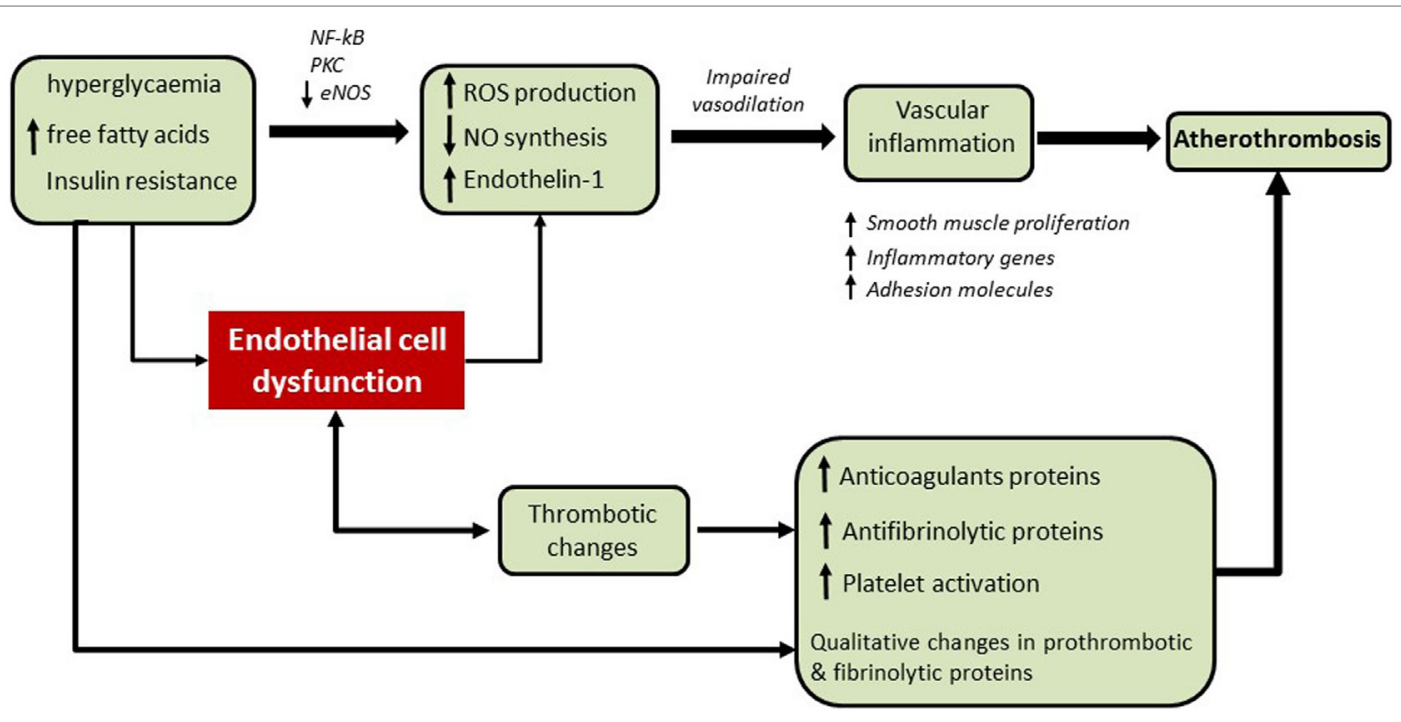

FIGURE 1 | The accelerated vascular pathology and enhanced thrombotic environment in diabetes. Endothelial dysfunction plays a key role in all stages of the atherosclerotic process. In the early stages of the disease, insulin resistance and increased levels of glucose and free fatty acids enhance the production of reactive oxygen species (ROS) and reduce nitric oxide (NO) synthesis via several mechanisms including activation of NF-kB and protein kinase C (PKC) signaling and reduction of endothelial NO synthase (eNOS) activity. Endothelial dysfunction contributes to the impairment of vasodilation, expression of adhesion molecules, and further vascular inflammation. In the latter stages of the disease, endothelial dysfunction results in increased platelet activation and a prothrombotic/hypofibrinolytic environment which facilitates vascular occlusion and atherothrombosis.

substrate-1 by c-Jun amino-terminal kinase (JNK) and protein kinase C (PKC) causing downregulation of the PI3-kinase/Akt pathway and the glucose transporter GLUT-4. Suppression of the PI3-kinase/Akt pathway leads to reduced eNOS activity and decreased NO production. Furthermore, the increased oxidative stress and hyperglycemia, stimulate vascular inflammation via several cellular mechanisms, including promoting activation of $\mathrm{PKC}$ and NF- $\kappa \mathrm{B}$ signaling. Secretion of cytokines IL- 1 and TNF- $\alpha$ enhances NF- $\kappa \mathrm{B}$ activity and production of adhesion molecules by ECs further aggravating the inflammatory process $(21,22)$.

Figure 2 summarizes the main mechanistic pathways operating to increase vascular inflammation in diabetes.

\section{Thrombotic Changes in Diabetes}

The metabolic changes including IR and hyperglycemia are associated with both increased platelet activation and reduced response to antiplatelet therapy, which have been extensively reviewed elsewhere (23-26). Briefly, there are two main types of antiplatelet agents that are currently used for long-term therapy in diabetes. The first targets the thromboxane pathway, represented by aspirin, whereas the second targets the P2Y12 pathway, and this family of drugs currently includes three agents: clopidogrel, prasugrel, and ticagrelor. More antiplatelet agents are in development that target additional pathways (26).

Following myocardial infarction, dual antiplatelet therapy (DAPT) is used employing agents that target the thromboxane and P2Y12 pathways. However, inhibitors of the P2Y12 pathway seem to vary in efficacy. In the TRITON trial, DAPT with aspirin and prasugrel following myocardial infarction was superior to aspirin and clopidogrel but at the expense of increased bleeding events, failing to overall improve clinical outcome. A sub-analysis of diabetes patients, however, has shown reduction in further ischemic events without a significant increase in bleeding risk (27), making prasugrel particularly useful for patients with diabetes. The newer P2Y12 inhibitor ticagrelorhas also shown both biochemical and clinical superiority to clopidogrel when used in combination with aspirin following myocardial infarction, an effect that was observed in both diabetes and non-diabetes patients without an increase in bleeding risk (28-31). Moreover, the PEGASUS-TIMI 54 trial showed that ticagrelor addition to background aspirin therapy in patients with stable coronary artery disease caused significant reduction of cardiovascular risk compared with the placebo group (32). The previously documented reduced efficacy of clopidogrel in diabetes does not seem to apply to the newer agent ticagrelor, showing the progress made at inhibiting P2Y12 pathway in diabetes. In contrast, the inhibition of the thromboxane pathway by aspirin remains an area of debate. Given the short half-life of aspirin and the increased platelet turnover in this condition, the use of twice daily aspirin in diabetes has been advocated. Indeed, clinical studies have shown a significant reduction in platelet reactivity to thromboxane when using aspirin twice daily vs once/day (33-36). However, it remains unclear whether twice daily aspirin affects clinical outcome and studies in this area are lacking.

A relatively recent development is the implication of reticulated platelets in atherothrombotic events (37). These are immature platelets that show resistance to the action of antiplatelet therapy $(38,39)$. However, the degree of resistance appears to differ comparing antiplatelet agents, with ticagrelor the least affected (40). Interestingly, a recent study has shown that poorly controlled diabetes is characterized by increased circulating reticulated platelets through induction of an 


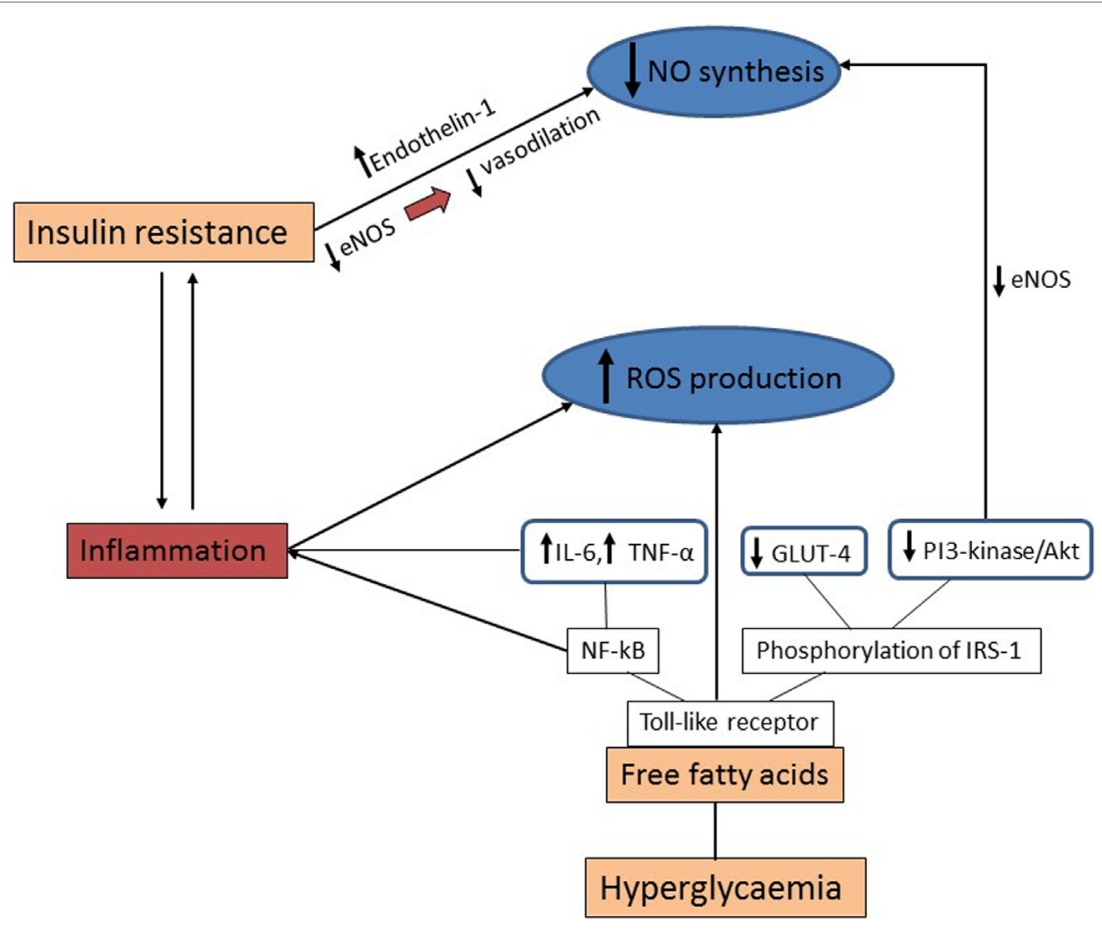

FIGURE 2 | Mechanistic pathways for increased vascular inflammation in diabetes. Insulin resistance inhibits nitric oxide (NO) synthesis by reducing vasodilation via decreased activity of endothelial NO synthase (eNOS) together with increased production of vasoconstrictors such as endothelin-1. Hyperglycemia and increased levels of free fatty acids enhance the production of reactive oxygen species (ROS) and reduce NO synthesis via several cellular mechanisms. Free fatty acids bind to toll-like receptor which activates the NF-kB pathway and stimulates inflammation by increasing interleukin (IL)- 6 and tumor necrosis factor (TNF)- $\alpha$. Additionally, toll-like receptor stimulates the phosphorylation of insulin receptor substrate-1 (IRS-1) followed by downregulation of the PI3-kinase/Akt pathway and the glucose transporter GLUT-4, consequently resulting in reduction of NO production.

inflammatory pathway that leads to increased thrombopoietin production. A correlation between $\mathrm{HbA} 1 \mathrm{c}$ and reticulated platelets was found in patients with T2DM and improving glycemic control, using an agent in the sodium glucose co-transporter- 2 (SGLT2) inhibitor family, reduced reticulated thrombocytosis in mice. These findings indicate that one strategy for improved efficacy of antiplatelet agents is to reduce circulating reticulated platelets, which can be achieved by lowering glucose levels using SGLT2 inhibitors. This in turn may help to reduce cardiovascular risk in patients with diabetes (41). Indeed, studies on SGLT2 inhibitors have shown reduction in the composite end point of myocardial infarction, stroke, and cardiovascular death (42) and controlling platelet reactivity may be one of the mechanisms involved.

In addition to enhanced platelet activation, diabetes is associated with increased plasma levels and/or activity of various coagulation factors. The net result is an enhanced susceptibility to forming fibrin networks which are characterized by increased density and resistance to fibrinolysis $(43,44)$. For example, tissue factor (TF) and factor VII (FVII) levels are increased in diabetes, which in turn explains the enhanced production of thrombin leading to higher risk of clot formation. Moreover, plasma levels of fibrinogen are increased in diabetes, as part of the ongoing lowgrade inflammation, which contributes to formation of denser clots. In addition, anticoagulants, such as thrombomodulin and protein $\mathrm{C}$, are reduced in diabetes further predisposing to the prothrombotic environment $(43,45)$. A key antifibrinolytic protein is plasminogen activator inhibitor-1 (PAI-1), which inhibits conversion of plasminogen to active plasmin. Plasma levels of PAI-1 are increased in diabetes, thereby impairing the fibrinolytic process. It should be noted that patients with type 2 diabetes, but not type 1 diabetes, have increased levels of PAI-1 indicating that IR, rather than hyperglycemia per se, drives the increased production of this antifibrinolytic protein, a concept that was confirmed using in vitro and in vivo studies $(9,44$, $46,47)$. Therefore, ameliorating IR would have more of an effect on PAI-1 levels than simply improving glycemia in diabetes, highlighting some of the complexities involved in the management of this condition.

In addition to quantitative changes, qualitative abnormalities have been documented in diabetes that increase thrombosis risk. This includes altered fibrinogen posttranslational modifications, including increased glycation and oxidation, resulting in denser fibrin networks (48-51). Also, we have shown that hyperglycemia can directly affect the fibrinolytic system by increasing plasminogen glycation, which impairs conversion to plasmin and adversely affects protein activity. Interestingly, a relatively modest decrease in plasma glucose levels improves plasminogen function, demonstrating the importance of optimizing glycemic control in these patients (52). 
An interesting, and potentially clinically relevant, mechanism for impaired fibrin clot lysis in diabetes is focused on increased incorporation of antifibrinolytic proteins into the clot. Alpha 2 -antiplasmin is cross-linked into the fibrin clot and it inhibits plasmin by forming a stable complex with this protein. It has been reported that type 1 diabetes patients have increased alpha 2-antiplasmin incorporation into their fibrin clots $(47,53)$. Similarly, we have shown that complement C3 incorporation into diabetes clots is increased in diabetes and directly prolongs clot lysis (54, 55). Moreover, C3 plasma levels were independent predictors of clot lysis in a large cohort of type 2 diabetes patients $(56,57)$. Taken together, modulating incorporation of antifibrinolytic proteins into diabetes clots may represent a new therapeutic strategy to reduce thrombotic risk in diabetes. The main mechanisms operating to increase thrombosis risk and may represent future therapeutic targets in diabetes are summarized in Figure 3.

\section{From Bench to Bedside}

Given the pathophysiological mechanisms involved in vascular pathology in diabetes, there are two main areas to target: slowing the progression of atherosclerosis and reducing the prothrombotic/hypofibrinolytic environment. Therefore, current therapies are directed at improving endothelial function, reducing systemic inflammation, and controlling the enhanced thrombotic environment.

\section{Targeting Atherosclerosis}

In general, improving glycemia and reducing IR, which is part of the clinical management strategy in diabetes, have key roles in halting the accelerated atherosclerotic process in this condition.

A number of existing agents, and others in development, target the inflammatory pathway to reduce atherosclerosis risk. Statins, known for their ability to decrease cholesterol levels, have also been shown to affect the inflammatory response and this dual mode of action explains the efficacy of this class of drugs in reducing vascular events in diabetes (58-60).

The initial enthusiasm with preclinical studies involving the inhibitor of phospholipase A2 (PLA2) darapladip quickly faded with the failure of this agent to reduce coronary vascular events. The clinical findings suggest that this enzyme is a biomarker of vascular pathology rather than a factor having a direct role in pathogenesis. Inadequate dosing and off-target effect(s) have also been blamed for failing to demonstrate a clinical benefit with this agent so far (61). More studies are currently ongoing that will fully clarify the role of PLA2 as an agent that modifies the atherosclerotic process $(62,63)$.

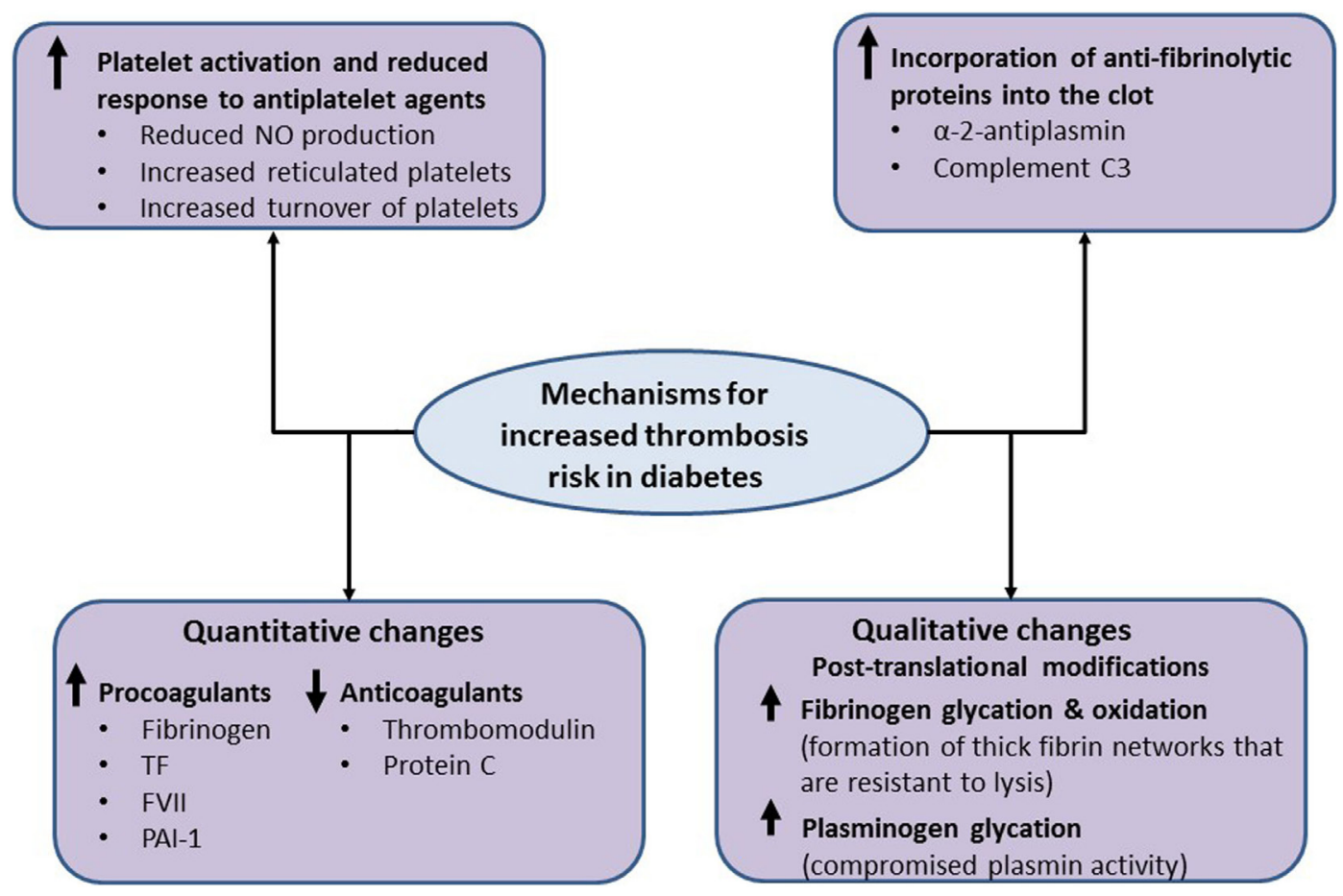

FIGURE 3 | Mechanistic pathways for increased thrombosis risk in diabetes. The metabolic changes in diabetes are associated with increased platelet activation, secondary to reduced nitric oxide (NO) production, an increase in reticulated platelets and increased platelet turnover, which can be only partially controlled by antiplatelet therapy. Diabetes is also associated with increased plasma levels of procoagulants and the antifibrinolytic protein levels, including fibrinogen, tissue factor (TF), factor VII (FVII), and plasminogen activator inhibitor-1 (PAl-1) as well as decreased levels of anticoagulants, including thrombomodulin and protein C. Moreover, qualitative changes in coagulation proteins, including increased oxidation and glycation of fibrinogen, have also been reported in diabetes, which result in the formation of thick fibrin networks that are resistant to lysis. Increased glycation of plasminogen compromises conversion to plasmin and alters protein activity. Finally, increased incorporation of antifibrinolytic proteins, such as $\alpha 2$-antiplasmin and complement C3, into the clot impairs fibrinolysis and may represent a new therapeutic approach to reduce thrombosis risk in diabetes. 
Experimental studies and preclinical models have indicated that IL-1 $\beta$ blockade is effective at preventing coronary artery disease. A recent study involving 10,061 patients with previous myocardial infarction and C-reactive protein levels above $2 \mathrm{mg} / \mathrm{l}$, showed that IL-1 inhibition, using Canakinumab, reduced the composite end point of non-fatal myocardial infarction, non-fatal stroke, and cardiovascular death by 15 and 14\% using 150 and $300 \mathrm{mg}$ of this agent, respectively (injected once every 3 months). However, there was no difference in all-cause mortality, which may be related to increased fatal infection in the Canakinumab arm of the study.

Antioxidants have been repeatedly considered as potential drugs for the prevention and therapy of atherosclerosis given the role of ROS in the pathogenesis of atherosclerosis (64). However, clinical studies with antioxidants have been generally disappointing; a well-conducted double-blind, randomized, placebocontrolled study involving 6,144 patients with established CVD has shown that the antioxidant succinobucol (AGI-1067) has no beneficial effect on vascular outcome, dampening the enthusiasm toward such therapy (65). The generally negative results with various antioxidant therapies suggest that targeting a single pathway involved in vascular pathology is perhaps not enough for translation into clinical benefit. The establishment of the European consortium for the study of ROS should further help to shed more light on the role of this pathway as a therapeutic target in vascular pathology, including high-risk conditions such as diabetes (66).

Given the pivotal role of endothelial dysfunction in vascular pathology, a number of agents that improve EC function are currently in clinical use and others are under development. Angiotensin-converting (ACE) inhibitors, angiotensin II-receptor blockers (ARB), some $\beta$ blockers, and calcium channel blockers, all modulate EC function. However, not all have the same clinical effects; for example, ACEI convincingly provide protection from future vascular events, whereas the case for ARB is less clear despite targeting a largely similar pathway.

Compounds that act directly on guanylate cyclase (sGC), a key enzyme of the NO signaling pathway, have also been investigated in preclinical studies. The therapeutic potential of sGC activators (cinaciguat or ataciguat) and sGC stimulators (riociguat) has been explored in animal models and clinical trials (67). In a recent animal study, it was demonstrated that a sGC activator offered renal protection against the progression of nephropathy induced by type 2 diabetes in obese rats (68). However, it remains unclear whether sGC activators can modulate the risk of vascular occlusion in man, and this remains an area for further research.

While all these agents can improve endothelial dysfunction by lowering blood pressure, it is clear that additional mechanisms operate to explain the difference in vascular outcome $(69,70)$. It has been reported that the thiazolinedione family of hypoglycemic agents, improve endothelial dysfunction in patients with type 2 diabetes by modulating IR $(71,72)$. Although pioglitazone treatment showed protection from cardiovascular events in diabetes (73), treatment with rosiglitazone therapy was associated with an increase in vascular events (74). This shows that two agents within the same class can have a different clinical outcome, highlighting the difficulties in treating vascular disease in diabetes.
Experimental agents to improve EC function include eNOStranscription enhancer and agents that inhibit phosphodiesterase-5 (PDE-5) and sphingosine-1-phosphate $(75,76)$. It has been shown that the eNOS-transcription enhancer AVE3085 restored endothelial function in a hypertensive rat model suggesting that drugs regulating eNOS may be considered as therapeutic targets (77). Furthermore, PDE-5 inhibitors upregulate eNOS expression and, therefore, NO production. It has been reported that these inhibitors can improve endothelial function and control platelet activation in patients with coronary artery disease and have also been shown to improve vascular relaxation in diabetic rats $(75,78)$. Another target that gained an interest is sphingosine1-phosphate, which affects the function of cells involved in the atherosclerotic process, including monocyte attachment and proliferation of smooth muscle cells (79).

Aging and diabetes both cause vascular dysfunction and the existence of both conditions has an additive effect in vascular damage, leading to increased vascular inflammation and cardiovascular risk (80). So far, however, there has been little research on the mechanisms of vascular inflammation due to both aging and diabetes, which would be particularly helpful to address vascular disease in older patients with diabetes.

It has recently been demonstrated that following a coronary ischemic event, a single dose of reconstituted HDL increased cardiac glucose uptake and reduced infarct size in both metabolically normal and insulin-resistant mice (81). While these data are interesting, further studies are needed to clarify the role of this approach in modulating vascular risk in man.

Finally, several studies have investigated the role of miRNAs in endothelial dysfunction in diabetes. It has been suggested that these noncoding, single-stranded RNA molecules which are implicated in key processes such as IR and $\beta$-cell function, may contribute to the development of prognostic tools or therapeutic targets of CVD in diabetes (82). For example, miR-155 has been implicated with atherosclerosis via modulation of actin cytoskeleton organization in ECs, and it was reported that inhibition of miR- 155 can reduce atherosclerotic plaques (83). Platelet miR-223 was reduced in patients with diabetes and in mice which had an effect on platelet function. Platelets from miR-223 knockout mice had increased aggregation and potential for thrombus formation compared to platelets from wild-type mice $(84,85)$.

The various inflammatory pathways that may represent therapeutic targets to reduce vascular risk in diabetes are summarized in Figure 4.

\section{Targeting Thrombosis}

The thrombotic potential can be modulated both indirectly and directly. The former includes measures to reduce IR, optimize glycemia, and improve endothelial dysfunction. The latter concentrates on antiplatelet therapy as well as agents that target coagulation proteins.

\section{Indirect Measures to Improve the Thrombotic Environment}

Diabetes-specific measures to improve the thrombotic environment concentrate on ameliorating IR and improving glycemia. 


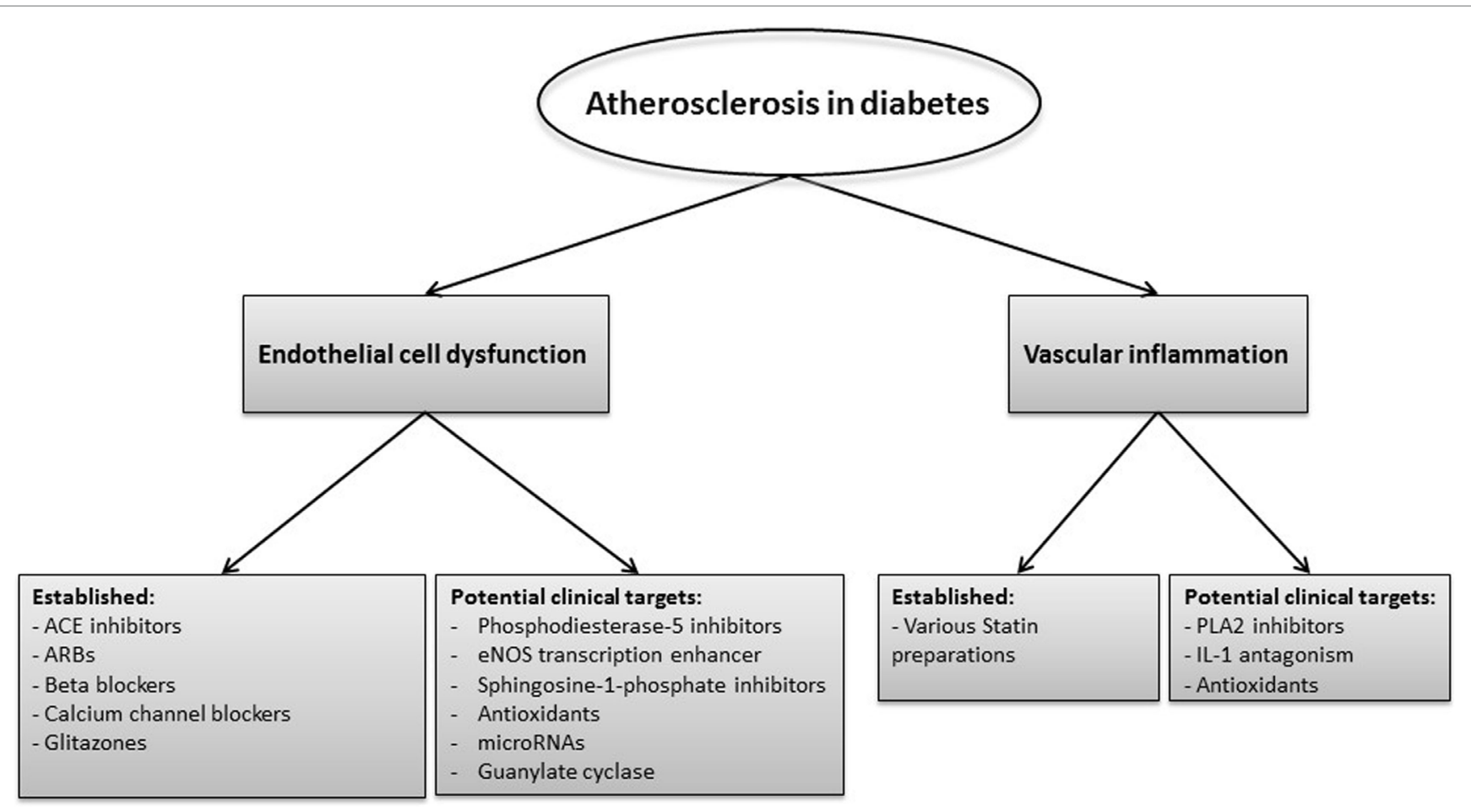

FIGURE 4 | Inflammatory pathways that are currently used or may represent therapeutic targets to reduce vascular risk in diabetes. Current therapies and others in development focus on improving the endothelial cell function and reducing vascular inflammation. Established therapies to target endothelial dysfunction are angiotensin converting (ACE) inhibitors, angiotensin II-receptor blockers (ARBs), beta blockers, calcium channel blockers, and glitazones, whereas agents such as phosphodiesterase-5 inhibitors, endothelial nitric oxide synthase (eNOS) transcription enhancer, and microRNAs represent potential future therapies. Statins are widely used to reduce vascular risk and in addition to their cholesterol lowering effect they reduce vascular inflammation. Other potential targets to reduce vascular inflammation include of phospholipase A2 (PLA2) inhibitors as well as interleukin (IL)-1 antagonists and antioxidants.

This can be achieved by simple measures, such as increased exercise/adhering to a healthy diet through to sophisticated treatment regimen of intensive glycemic control. Improving glycemia reduces platelet activation, modulates fibrin clot structure, and improves efficiency of the fibrinolytic system thus ameliorating the prothrombotic environment in diabetes. However, the shortmedium term clinical effects of improving glycemia on vascular events are debatable with studies showing a benefit, no effect and even harm (86-88). The inconsistent results of glycemic studies may be related to precipitation of hypoglycemia with tight glycemic control, which can be prothrombotic. We have shown that an episode of hypoglycemia creates a prothrombotic and hypofibrinolytic environment for at least 1 week (89), explaining the association between hypoglycemia, cardiovascular events, and mortality $(90,91)$. Therefore, hypoglycemic agents with lower risk of hypoglycemia should be considered in higher vascular risk patients with diabetes. In support of this concept, three relatively recent trials with hypoglycemic agents that are associated with low risk of hypoglycemia have shown improved vascular outcome (92-94). It should be acknowledged, however, that the beneficial effects of these newer hypoglycemia agents are not solely related to avoidance of hypoglycemia and the favorable clinical outcome is likely to be due to modulation of a number of cardiovascular risk factors.
In addition to glycemia, there has been an interest in the antithrombotic properties of omega-3 polyunsaturated fatty acids (n-3 PUFAs). However, a recent study demonstrated that treatment with n-3 PUFAs failed to modulate fibrin clot properties, platelet activation, or inflammation in patients with atherosclerosis and type 2 diabetes (95).

\section{Direct Measures to Improve the Thrombotic Environment}

Antiplatelet agents remain a cornerstone in the management of the thrombotic environment in diabetes. However, the best treatment regimen at various stages of the vascular pathology is yet to be determined; this can be divided into primary prevention, secondary prevention immediately following an event and longterm secondary prevention. This topic is reviewed extensively elsewhere $(26,60,96,97)$ and we will only provide here a clinically orientated practical summary.

\section{ANTIPLATELET AGENTS}

\section{Primary Prevention}

Aspirin irreversibly inhibits cyclo-oxygenase (COX) enzymes, at lower doses exhibiting relative selectivity for COX1, which 
is responsible for the synthesis of thromboxane $\mathrm{A}_{2}\left(\mathrm{TXA}_{2}\right)$, a prothrombotic and vasoconstrictive eicosanoid. At higher doses, aspirin can also inhibit COX2, leading to the unwanted reduction in production of prostacyclin $\left(\mathrm{PGI}_{2}\right)$ an antithrombotic and vasodilatory agent (98). In addition to platelet inhibition, aspirin appears to affect the fibrin network structure and fibrinolysis, which may also contribute to its clinical antithrombotic effects (99).

Until relatively recently, aspirin was used for primary prevention in patients with diabetes, although there was no clear evidence supporting such an approach. A number of studies investigating aspirin in primary vascular protection in diabetes failed to show a benefit, including PPP trial, JPAD, and POPADAD studies, and therefore, current guidelines do not advocate the use of this agent for primary prevention (100-103). It should be acknowledged that none of these studies was adequately powered to give a definitive answer and results from an ongoing large study are currently awaited that will clarify the use of aspirin for primary prevention in diabetes $\left(\mathrm{ASCEND}^{2}\right)$. The guidelines adopted a pragmatic approach, however, by recommending aspirin use for primary prevention in those at higher risk without clearly defining this group.

One of the issues that remain unresolved is the optimal dosing regimen of aspirin in diabetes. Given the increased platelet turnover in diabetes and the relatively short half-life of aspirin, this agent may fail to provide $24 \mathrm{~h}$ coverage $(97,104)$. Therefore, studies have investigated twice daily administration of aspirin, which appears to improve the platelet inhibitory effect, although the clinical value of this approach remains unclear (34-36). This has been alluded to in joint ESC/EASD guidelines but no management recommendations were made due to lack of evidence (103).

\section{Secondary Cardiovascular Prevention}

Aspirin is used in combination with other antiplatelet agents that target the P2Y12 pathway, following acute coronary syndrome (ACS) in diabetes patients and individuals with no diabetes. Of the three agents that target the P2Y12 pathway, both prasugrel and ticagrelor showed superiority to clopidogrel in improving vascular outcome in patients with diabetes $(31,105,106)$. A plausible explanation is related to the need to metabolize clopidogrel from the inactive to the active form, which is simpler process with prasugrel and not required at all with ticagrelor.

Dual antiplatelet therapy is usually continued for a period of 1 year after an ACS to be followed by aspirin only therapy that is continued indefinitely. However, recent evidence indicates that longer-term DAPT therapy with aspirin and ticagrelor offers a survival advantage in diabetes patients, unlike those without diabetes (107). The safety and cost effectiveness of this approach requires further analysis and/or studies before routinely recommending long-term DAPT in patients with diabetes $(26,31$, 105, 106).

An inherent difficulty in optimizing antiplatelet therapy in diabetes is related to the heterogeneity of this condition and the

${ }^{2}$ https://clinicaltrials.gov/ct2/show/NCT00135226. variable vascular risk according to duration of diabetes, treatment modalities, and presence of microvascular complications. In order to optimize antiplatelet therapy in diabetes, there are a number of questions that remain unanswered, including: (i) Is an alternative dosing of aspirin required in diabetes? (ii) How long to continue treatment with DAT following ACS? (iii) Are different antiplatelet regimen required in different groups of diabetes patients, particularly for primary prevention? (iv) Are additional antiplatelet agents that target other pathways required? Addressing these questions will require large clinical outcome studies which are both time consuming and expensive. Therefore, using surrogate markers, such as platelet activation tests, may provide provisional data justifying clinical outcome studies. In other words, an integrated bench to bedside approach is perhaps the most cost effective way to investigate newer antithrombotic agents or analyze alternative application of existing agents.

\section{AGENTS TARGETING THE COAGULATION PATHWAY}

\section{Established Therapies}

Proteins of the contact system have been investigated and considered as therapeutic targets due to their important role in the initiation of thrombosis. TF is expressed by exposed vascular smooth muscle cells at the atherosclerotic plaque rupture sites where it triggers the activation of FVII and the initiation of the coagulation cascade. Activation of FIX and FX by the TF/FVIIa complex then leads to the formation of FXa/FVa complex which converts prothrombin into thrombin (108).

Heparin is an indirect inhibitor of FX and prothrombin and is used in diabetes and non-diabetes subjects with ACS. It is mainly used in unfractionated form or as the low-molecular weight form of heparin, named enoxaparin, which has been suggested to be more effective than the unfractionated form of heparin (109). Another indirect inhibitor of FX which was reported to be as effective as enoxaparin or unfractionated heparin is fondaparinux (110). However, unlike heparin, fondaparinux fails to inhibit thrombin.

The recent development of direct oral anticoagulants has further helped by offering a more targeted inhibition of the protein arm of coagulation. Bivalirudin is a direct inhibitor of thrombin which has been reported to be superior to heparin as a therapy for diabetes patients with ACS due to the significant reduction in bleeding complications in some studies $(111,112)$. The COMPASS study, involving over 27,000 patients with stable coronary artery disease, has recently shown that combination of rivaroxaban (FX inhibitor) with aspirin is superior to aspirin alone in preventing vascular events, an observation that applied to both patients with and without diabetes (113). However, there was a 70\% increase in bleeding risk in patients receiving combination therapy, which is a concern and will have implications for the widespread use of such a therapy.

\section{Experimental Therapies}

FXII and FXI are involved upstream in the coagulation system and have been considered as potential therapeutic targets for 


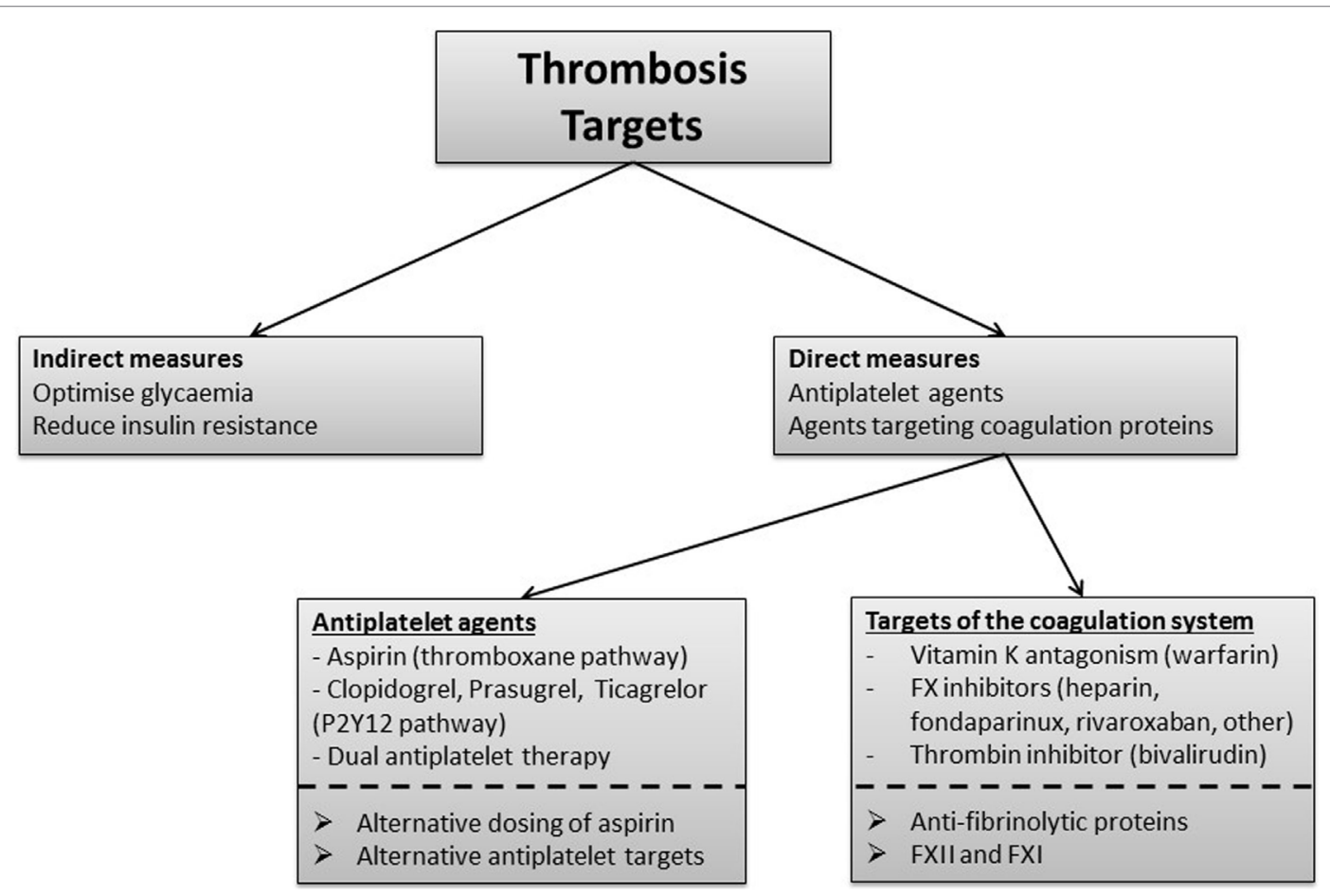

FIGURE 5 | Thrombotic pathways that represent current and potential therapeutic targets in diabetes. Indirect measures to improve the thrombotic environment in diabetes focus on optimizing glycemic control by lowering glucose levels while avoiding hypoglycemia and also by reducing insulin resistance. Antiplatelets and agents that target the coagulation system comprise the main direct measures to manage the thrombotic environment in diabetes. Aspirin targets the thromboxane pathway and is also used in combination with clopidogrel, prasugrel, or ticagrelor which target the P2Y12 pathway. Alternative antiplatelet targets are under consideration. Vitamin $\mathrm{K}$ antagonism reduces thrombosis risk but is associated with high risk of bleeding when combined with antiplatelet therapy, and therefore, not routinely used for atherothrombotic disease. Inhibitors of coagulation proteins FX and thrombin, such as heparin and direct oral anticoagulants, represent agents with promise in diabetes while targeting factor $(\mathrm{F}) \mathrm{XII}$ and $\mathrm{FXI}$ requires careful future evaluation. Alternative dosing of aspirin and reduction of incorporation of antifibrinolytic proteins into the clot may represent new approaches to improve clinical outcome in patients with diabetes.

thrombosis prevention. Activation of FXII triggers the initiation of the contact system and FXIIa converts prekallikrein to kallikrein. Kallikrein promotes the generation of additional FXIIa and the activation of FXI. Finally, FXIa activates FIX and promotes FX activation and generation of thrombin. The antithrombotic effects of targeting FXII and prekallikrein have been demonstrated in vivo using $\mathrm{FeCl} 3$ - induced and stenosis-induced models of venous thrombosis (114). Different approaches, such as the use of antibodies, small molecules and aptamers have been developed to target factor XII and FXI but the clinical efficacy and safety of such drugs in man are yet to be determined (115).

A crucial element of a successful antithrombotic therapy is maintaining a clinically acceptable risk/benefit ratio. This requires close understanding of the mechanistic pathways operating to increase thrombosis risk in diabetes. For example, it has been shown that both PI and complement C3 incorporation into diabetes clots is enhanced, which further compromises fibrinolysis (detailed above). Developing therapies that reduce incorporation of these proteins into diabetes clots will facilitate fibrinolysis, thus limiting thrombus formation while keeping bleeding risk to a minimum. Therefore, rather than full inhibition of one pathway, which compromises normal physiology and increases bleeding risk, what is perhaps required is partial inhibition of multiple pathways with a focus on those that show a diabetes-specific abnormality.

Potential treatments and targets to further reduce atherothrombosis risk in diabetes are summarized in Figure 5.

\section{CONCLUSION AND THE WAY FORWARD}

Research conducted for the prevention and treatment of atherothrombotic disease has seen major advances over the past few decades, which translated clinically into significant improvement in vascular mortality and morbidity. We now have a number of agents that limit the atherosclerotic process and also control the risk of thrombosis. Despite these advances, however, the risk of vascular disease in patients with diabetes remains unacceptably high with relatively poor prognosis following an ischemic event. Therefore, future work is required to develop more effective therapeutic agents to halt the accelerated atherosclerotic process, typically associated with diabetes. Moreover, work is needed to develop antithrombotic strategies that target diabetes-specific pathways, thereby maximizing benefit and limiting the risk of bleeding. These include alternative use of existing agents and development of novel agents. An example of the former is investigating the efficacy of twice daily aspirin regimen in diabetes, 
whereas the latter includes development of agents that target the hypofibrinolytic environment, a key abnormality in individuals with deranged glucose metabolism (44).

Finally, we should accept that diabetes is not a single clinical entity but a continuum of different stages of the condition with each having a different vascular risk. Therefore, in order to maximize benefit, future therapies aiming to reduce atherothrombotic risk in diabetes may require stratifying patients into different categories with each group having a "stage-specific" vascular management strategy. Admittedly, this will add to the complexity of clinical therapy, particularly as vascular risk will

\section{REFERENCES}

1. Prentki $\mathrm{M}$, Nolan CJ. Islet beta cell failure in type 2 diabetes. J Clin Invest (2006) 116(7):1802-12. doi:10.1172/JCI29103

2. Chang-Chen KJ, Mullur R, Bernal-Mizrachi E. Beta-cell failure as a complication of diabetes. Rev Endocr Metab Disord (2008) 9(4):329-43. doi:10.1007/ s11154-008-9101-5

3. Cerf ME. Beta cell dysfunction and insulin resistance. Front Endocrinol (2013) 4:37. doi:10.3389/fendo.2013.00037

4. Cleland SJ, Fisher BM, Colhoun HM, Sattar N, Petrie JR. Insulin resistance in type 1 diabetes: what is 'double diabetes' and what are the risks? Diabetologia (2013) 56(7):1462-70. doi:10.1007/s00125-013-2904-2

5. Emerging Risk Factors Collaboration, Di Angelantonio E, Kaptoge S, Wormser D, Willeit P, Butterworth AS, et al. Association of cardiometabolic multimorbidity with mortality. JAMA (2015) 314(1):52-60. doi:10.1001/ jama.2015.7008

6. Booth GL, Kapral MK, Fung K, Tu JV. Relation between age and cardiovascular disease in men and women with diabetes compared with non-diabetic people: a population-based retrospective cohort study. Lancet (2006) 368(9529):29-36. doi:10.1016/S0140-6736(06)68967-8

7. Hadi HA, Carr CS, Al Suwaidi J. Endothelial dysfunction: cardiovascular risk factors, therapy, and outcome. Vasc Health Risk Manag (2005) 1(3):183-98.

8. Ajjan R, Grant PJ. Coagulation and atherothrombotic disease. Atherosclerosis (2006) 186(2):240-59. doi:10.1016/j.atherosclerosis.2005.10.042

9. King R, Ajjan R. Hypoglycaemia, thrombosis and vascular events in diabetes. Expert Rev Cardiovasc Ther (2016) 14(10):1099-101. doi:10.1080/14779072. 2016.1215916

10. Davignon J, Ganz P. Role of endothelial dysfunction in atherosclerosis. Circulation (2004) 109(23 Suppl 1):III27-32. doi:10.1161/01. CIR.0000131515.03336.f8

11. Deanfield JE, Halcox JP, Rabelink TJ. Endothelial function and dysfunction: testing and clinical relevance. Circulation (2007) 115(10):1285-95. doi:10.1161/CIRCULATIONAHA.106.652859

12. Rajendran $P$, Rengarajan $T$, Thangavel J, Nishigaki $Y$, Sakthisekaran D, Sethi G, et al. The vascular endothelium and human diseases. Int J Biol Sci (2013) 9(10):1057-69. doi:10.7150/ijbs.7502

13. Gimbrone MA Jr, Garcia-Cardena G. Endothelial cell dysfunction and the pathobiology of atherosclerosis. Circ Res (2016) 118(4):620-36. doi:10.1161/ CIRCRESAHA.115.306301

14. Paneni F, Beckman JA, Creager MA, Cosentino F. Diabetes and vascular disease: pathophysiology, clinical consequences, and medical therapy: part I. Eur Heart J (2013) 34(31):2436-43. doi:10.1093/eurheartj/eht149

15. Hossain P, Kawar B, El Nahas M. Obesity and diabetes in the developing world - a growing challenge. N Engl J Med (2007) 356(3):213-5. doi:10.1056/ NEJMp068177

16. Kim JA, Montagnani M, Koh KK, Quon MJ. Reciprocal relationships between insulin resistance and endothelial dysfunction: molecular and pathophysiological mechanisms. Circulation (2006) 113(15):1888-904. doi:10.1161/CIRCULATIONAHA.105.563213

17. Kalani M. The importance of endothelin-1 for microvascular dysfunction in diabetes. Vasc Health Risk Manag (2008) 4(5):1061-8. doi:10.2147/VHRM. S3920

18. Zhang YN, Xie BD, Sun L, Chen W, Jiang SL, Liu W, et al. Phenotypic switching of vascular smooth muscle cells in the 'normal region' of aorta vary over time in each patient, but this "individualized care" approach is perhaps key to improve long-term outcome in this high-risk population.

\section{AUTHOR CONTRIBUTIONS}

NP designed the review, undertook the literature search, and wrote the manuscript and RA designed the review and critically reviewed the manuscript. Both authors agreed to the final manuscript.

from atherosclerosis patients is regulated by miR-145. J Cell Mol Med (2016) 20(6):1049-61. doi:10.1111/jcmm.12825

19. Shirwany NA, Zou MH. Arterial stiffness: a brief review. Acta Pharmacol Sin (2010) 31(10):1267-76. doi:10.1038/aps.2010.123

20. Schafer A, Alp NJ, Cai S, Lygate CA, Neubauer S, Eigenthaler M, et al. Reduced vascular NO bioavailability in diabetes increases platelet activation in vivo. Arterioscler Thromb Vasc Biol (2004) 24(9):1720-6. doi:10.1161/01. ATV.0000138072.76902.dd

21. Giacco F, Brownlee M. Oxidative stress and diabetic complications. Circ Res (2010) 107(9):1058-70. doi:10.1161/CIRCRESAHA.110.223545

22. Tabit CE, Chung WB, Hamburg NM, Vita JA. Endothelial dysfunction in diabetes mellitus: molecular mechanisms and clinical implications. Rev Endocr Metab Disord (2010) 11(1):61-74. doi:10.1007/s11154-010-9134-4

23. Ferroni P, Basili S, Falco A, Davi G. Platelet activation in type 2 diabetes mellitus. J Thromb Haemost (2004) 2(8):1282-91. doi:10.1111/ j.1538-7836.2004.00836.x

24. Schneider DJ. Factors contributing to increased platelet reactivity in people with diabetes. Diabetes Care (2009) 32(4):525-7. doi:10.2337/dc08-1865

25. Ferreiro JL, Gomez-Hospital JA, Angiolillo DJ. Platelet abnormalities in diabetes mellitus. Diab Vasc Dis Res (2010) 7(4):251-9. doi: $10.1177 / 1479164110383994$

26. Park Y, Franchi F, Rollini F, Angiolillo DJ. Antithrombotic therapy for secondary prevention in patients with diabetes mellitus and coronary artery disease. Circ J (2016) 80(4):791-801. doi:10.1253/circi.CJ-16-0208

27. Wiviott SD, Braunwald E, Angiolillo DJ, Meisel S, Dalby AJ, Verheugt FW, et al. Greater clinical benefit of more intensive oral antiplatelet therapy with prasugrel in patients with diabetes mellitus in the trial to assess improvement in therapeutic outcomes by optimizing platelet inhibition with prasugrel-thrombolysis in myocardial infarction 38. Circulation (2008) 118(16):1626-36. doi:10.1161/CIRCULATIONAHA.108.791061

28. ShimadaYJ,BansilalS, WiviottSD,BeckerRC,HarringtonRA,HimmelmannA, et al. Impact of glycoprotein IIb/IIIa inhibitors on the efficacy and safety of ticagrelor compared with clopidogrel in patients with acute coronary syndromes: analysis from the platelet inhibition and patient outcomes (PLATO) trial. Am Heart J (2016) 177:1-8. doi:10.1016/j.ahj.2016.03.015

29. Velders MA, Abtan J, Angiolillo DJ, Ardissino D, Harrington RA, Hellkamp A, et al. Safety and efficacy of ticagrelor and clopidogrel in primary percutaneous coronary intervention. Heart (2016) 102(8):617-25. doi:10.1136/ heartjnl-2015-308963

30. Kohli P, Wallentin L, Reyes E, Horrow J, Husted S, Angiolillo DJ, et al Reduction in first and recurrent cardiovascular events with ticagrelor compared with clopidogrel in the PLATO study. Circulation (2013) 127(6):673-80. doi:10.1161/CIRCULATIONAHA.112.124248

31. James S, Angiolillo DJ, Cornel JH, Erlinge D, Husted S, Kontny F, et al. Ticagrelor vs. clopidogrel in patients with acute coronary syndromes and diabetes: a substudy from the platelet inhibition and patient outcomes (PLATO) trial. Eur Heart J (2010) 31(24):3006-16. doi:10.1093/eurheartj/ ehq325

32. Bhatt DL, Bonaca MP, Bansilal S, Angiolillo DJ, Cohen M, Storey RF, et al. Reduction in ischemic events with ticagrelor in diabetic patients with prior myocardial infarction in PEGASUS-TIMI 54. J Am Coll Cardiol (2016) 67(23):2732-40. doi:10.1016/j.jacc.2016.03.529

33. Bethel MA, Harrison P, Sourij H, Sun Y, Tucker L, Kennedy I, et al. Randomized controlled trial comparing impact on platelet reactivity of 
twice-daily with once-daily aspirin in people with type 2 diabetes. Diabet Med (2016) 33(2):224-30. doi:10.1111/dme.12828

34. Dillinger JG, Drissa A, Sideris G, Bal dit Sollier C, Voicu S, Manzo Silberman S, et al. Biological efficacy of twice daily aspirin in type 2 diabetic patients with coronary artery disease. Am Heart J (2012) 164(4):600-6.e1. doi:10.1016/j. ahj.2012.06.008

35. Spectre G, Arnetz L, Ostenson CG, Brismar K, Li N, Hjemdahl P. Twice daily dosing of aspirin improves platelet inhibition in whole blood in patients with type 2 diabetes mellitus and micro- or macrovascular complications. Thromb Haemost (2011) 106(3):491-9. doi:10.1160/TH11-04-0216

36. Capodanno D, Patel A, Dharmashankar K, Ferreiro JL, Ueno M, Kodali M, et al. Pharmacodynamic effects of different aspirin dosing regimens in type 2 diabetes mellitus patients with coronary artery disease. Circ Cardiovasc Interv (2011) 4(2):180-7. doi:10.1161/CIRCINTERVENTIONS.110.960187

37. Murphy AJ, Bijl N, Yvan-Charvet L, Welch CB, Bhagwat N, Reheman A, et al. Cholesterol efflux in megakaryocyte progenitors suppresses platelet production and thrombocytosis. Nat Med (2013) 19(5):586-94. doi:10.1038/ nm.3150

38. Guthikonda S, Lev EI, Patel R, DeLao T, Bergeron AL, Dong JF, et al. Reticulated platelets and uninhibited COX-1 and COX-2 decrease the antiplatelet effects of aspirin. J Thromb Haemost (2007) 5(3):490-6. doi:10.1111/j.1538-7836.2007.02387.x

39. Ibrahim H, Nadipalli S, DeLao T, Guthikonda S, Kleiman NS. Immature platelet fraction (IPF) determined with an automated method predicts clopidogrel hyporesponsiveness. J Thromb Thrombolysis (2012) 33(2):137-42. doi:10.1007/s11239-011-0665-7

40. Armstrong PC, Hoefer T, Knowles RB, Tucker AT, Hayman MA, Ferreira PM, et al. Newly formed reticulated platelets undermine pharmacokinetically short-lived antiplatelet therapies. Arterioscler Thromb Vasc Biol (2017) 37(5):949-56. doi:10.1161/ATVBAHA.116.308763

41. Kraakman MJ, Lee MK, Al-Sharea A, Dragoljevic D, Barrett TJ, Montenont E, et al. Neutrophil-derived S100 calcium-binding proteins A8/A9 promote reticulated thrombocytosis and atherogenesis in diabetes. J Clin Invest (2017) 127(6):2133-47. doi:10.1172/JCI92450

42. Rastogi A, Bhansali A. SGLT2 inhibitors through the windows of EMPAREG and CANVAS trials: a review. Diabetes Ther (2017) 8(6):1245-51. doi:10.1007/s13300-017-0320-1

43. Alzahrani SH, Ajjan RA. Coagulation and fibrinolysis in diabetes. Diab Vasc Dis Res (2010) 7(4):260-73. doi:10.1177/1479164110383723

44. Kearney K, Tomlinson D, Smith K, Ajjan R. Hypofibrinolysis in diabetes: a therapeutic target for the reduction of cardiovascular risk. Cardiovasc Diabetol (2017) 16(1):34. doi:10.1186/s12933-017-0515-9

45. Creager MA, Luscher TF, Cosentino F, Beckman JA. Diabetes and vascular disease: pathophysiology, clinical consequences, and medical therapy: part I. Circulation (2003) 108(12):1527-32. doi:10.1161/01. CIR.0000091257.27563.32

46. Schneider DJ, Sobel BE. PAI-1 and diabetes: a journey from the bench to the bedside. Diabetes Care (2012) 35(10):1961-7. doi:10.2337/dc12-0638

47. Agren A, Jorneskog G, Elgue G, Henriksson P, Wallen H, Wiman B. Increased incorporation of antiplasmin into the fibrin network in patients with type 1 diabetes. Diabetes Care (2014) 37(7):2007-14. doi:10.2337/dc13-1776

48. Lados-Krupa A, Konieczynska M, Chmiel A, Undas A. Increased oxidation as an additional mechanism underlying reduced clot permeability and impaired fibrinolysis in type 2 diabetes. J Diabetes Res (2015) 2015:456189. doi:10.1155/2015/456189

49. Pieters M, van ZylDG, Rheeder P, JerlingJC, Lootsdu T, vanderWesthuizen FH, et al. Glycation of fibrinogen in uncontrolled diabetic patients and the effects of glycaemic control on fibrinogen glycation. Thromb Res (2007) 120(3):439-46. doi:10.1016/j.thromres.2006.10.016

50. Svensson J, Bergman AC, Adamson U, Blomback M, Wallen H, Jorneskog G. Acetylation and glycation of fibrinogen in vitro occur at specific lysine residues in a concentration dependent manner: a mass spectrometric and isotope labeling study. Biochem Biophys Res Commun (2012) 421(2):335-42. doi:10.1016/j.bbrc.2012.03.154

51. Pieters M, Covic N, Loots du T, van der Westhuizen FH, van Zyl DG, Rheeder P, et al. The effect of glycaemic control on fibrin network structure of type 2 diabetic subjects. Thromb Haemost (2006) 96(5):623-9.

52. Ajjan RA, Gamlen T, Standeven KF, Mughal S, Hess K, Smith KA, et al. Diabetes is associated with posttranslational modifications in plasminogen resulting in reduced plasmin generation and enzyme-specific activity. Blood (2013) 122(1):134-42. doi:10.1182/blood-2013-04-494641

53. Al-Horani RA. Serpin regulation of fibrinolytic system: implications for therapeutic applications in cardiovascular diseases. Cardiovasc Hematol Agents Med Chem (2014) 12(2):91-125. doi:10.2174/1871525712666141106095927

54. Howes JM, Richardson VR, Smith KA, Schroeder V, Somani R, Shore A, et al. Complement C3 is a novel plasma clot component with anti-fibrinolytic properties. Diab Vasc Dis Res (2012) 9(3):216-25. doi:10.1177/1479164111432788

55. Hess K, Alzahrani SH, Mathai M, Schroeder V, Carter AM, Howell G, et al. A novel mechanism for hypofibrinolysis in diabetes: the role of complement C3. Diabetologia (2012) 55(4):1103-13. doi:10.1007/s00125-011-2301-7

56. Hess K, Alzahrani SH, Price JF, Strachan MW, Oxley N, King R, et al. Hypofibrinolysis in type 2 diabetes: the role of the inflammatory pathway and complement C3. Diabetologia (2014) 57(8):1737-41. doi:10.1007/ s00125-014-3267-z

57. Neergaard-Petersen S, Hvas AM, Kristensen SD, Grove EL, Larsen SB, Phoenix F, et al. The influence of type 2 diabetes on fibrin clot properties in patients with coronary artery disease. Thromb Haemost (2014) 112(6):114250. doi:10.1160/TH14-05-0468

58. Rosenson RS. Statins in atherosclerosis: lipid-lowering agents with antioxidant capabilities. Atherosclerosis (2004) 173(1):1-12. doi:10.1016/ S0021-9150(03)00239-9

59. Schonbeck U, Libby P. Inflammation, immunity, and HMG-CoA reductase inhibitors: statins as antiinflammatory agents? Circulation (2004) 109(21 Suppl 1):II18-26. doi:10.1161/01.CIR.0000129505.34151.23

60. Chan KY, Boucher ES, Gandhi PJ, Silva MA. HMG-CoA reductase inhibitors for lowering elevated levels of C-reactive protein. Am J Health Syst Pharm (2004) 61(16):1676-81.

61. Hassan M. STABILITY and SOLID-TIMI 52: lipoprotein associated phospholipase A2 (Lp-PLA2) as a biomarker or risk factor for cardiovascular diseases. Glob Cardiol Sci Pract (2015) 2015:6. doi:10.5339/gcsp.2015.6

62. Charo IF, Taub R. Anti-inflammatory therapeutics for the treatment of atherosclerosis. Nat Rev Drug Discov (2011) 10(5):365-76. doi:10.1038/ $\operatorname{nrd} 3444$

63. Rosenson RS, Hurt-Camejo E. Phospholipase A2 enzymes and the risk of atherosclerosis. Eur Heart J (2012) 33(23):2899-909. doi:10.1093/eurheartj/ ehs 148

64. Mangge H, Becker K, Fuchs D, Gostner JM. Antioxidants, inflammation and cardiovascular disease. World J Cardiol (2014) 6(6):462-77. doi:10.4330/wjc. v6.i6.462

65. Tardif JC, McMurray JJ, Klug E, Small R, Schumi J, Choi J, et al. Effects of succinobucol (AGI-1067) after an acute coronary syndrome: a randomised, double-blind, placebo-controlled trial. Lancet (2008) 371(9626):1761-8. doi:10.1016/S0140-6736(08)60763-1

66. Egea J, Fabregat I, Frapart YM, Ghezzi P, Gorlach A, Kietzmann T, et al. European contribution to the study of ROS: a summary of the findings and prospects for the future from the COST action BM1203 (EU-ROS). Redox Biol (2017) 13:94-162. doi:10.1016/j.redox.2017.05.007

67. Stasch JP, Pacher P, Evgenov OV. Soluble guanylate cyclase as an emerging therapeutic target in cardiopulmonary disease. Circulation (2011) 123(20):2263-73. doi:10.1161/CIRCULATIONAHA.110.981738

68. Boustany-Kari CM, Harrison PC, Chen H, Lincoln KA, Qian HS, Clifford H, et al. A soluble guanylate cyclase activator inhibits the progression of diabetic nephropathy in the ZSF1 rat. J Pharmacol Exp Ther (2016) 356(3):712-9. doi:10.1124/jpet.115.230706

69. Fukao K, Shimada K, Hiki M, Kiyanagi T, Hirose K, Kume A, et al. Effects of calcium channel blockers on glucose tolerance, inflammatory state, and circulating progenitor cells in non-diabetic patients with essential hypertension: a comparative study between azelnidipine and amlodipine on glucose tolerance and endothelial function - a crossover trial (AGENT). Cardiovasc Diabetol (2011) 10:79. doi:10.1186/1475-2840-10-79

70. Okamura T, Tawa M, Geddawy A, Shimosato T, Iwasaki H, Shintaku H, et al. Effects of atorvastatin, amlodipine, and their combination on vascular dysfunction in insulin-resistant rats. J Pharmacol Sci (2014) 124(1):76-85. doi:10.1254/jphs.13178FP

71. Papathanassiou K, Naka KK, Kazakos N, Kanioglou C, Makriyiannis D, Pappas K, et al. Pioglitazone vs glimepiride: differential effects on vascular endothelial function in patients with type 2 diabetes. Atherosclerosis (2009) 205(1):221-6. doi:10.1016/j.atherosclerosis.2008.11.027 
72. Versari D, Daghini E, Virdis A, Ghiadoni L, Taddei S. Endothelial dysfunction as a target for prevention of cardiovascular disease. Diabetes Care (2009) 32(Suppl 2):S314-21. doi:10.2337/dc09-S330

73. Dormandy JA, Charbonnel B, Eckland DJ, Erdmann E, Massi-Benedetti M, Moules IK, et al. Secondary prevention of macrovascular events in patients with type 2 diabetes in the PROactive study (PROspective pioglitAzone Clinical Trial In macroVascular Events): a randomised controlled trial. Lancet (2005) 366(9493):1279-89. doi:10.1016/S0140-6736(05)67528-9

74. Nissen SE, Wolski K. Rosiglitazone revisited: an updated meta-analysis of risk for myocardial infarction and cardiovascular mortality. Arch Intern Med (2010) 170(14):1191-201. doi:10.1001/archinternmed.2010.207

75. Schafer A, Fraccarollo D, Pfortsch S, Flierl U, Vogt C, Pfrang J, et al. Improvement of vascular function by acute and chronic treatment with the PDE-5 inhibitor sildenafil in experimental diabetes mellitus. Br J Pharmacol (2008) 153(5):886-93. doi:10.1038/sj.bjp.0707459

76. Cheang WS, Wong WT, Tian XY, Yang Q, Lee HK, He GW, et al. Endothelial nitric oxide synthase enhancer reduces oxidative stress and restores endothelial function in db/db mice. Cardiovasc Res (2011) 92(2):267-75. doi:10.1093/ cvr/cvr233

77. Yang Q, Xue HM, Wong WT, Tian XY, Huang Y, Tsui SK, et al. AVE3085, an enhancer of endothelial nitric oxide synthase, restores endothelial function and reduces blood pressure in spontaneously hypertensive rats. $\mathrm{Br}$ J Pharmacol (2011) 163(5):1078-85. doi:10.1111/j.1476-5381.2011.01308.x

78. Su JB. Vascular endothelial dysfunction and pharmacological treatment. World J Cardiol (2015) 7(11):719-41. doi:10.4330/wjc.v7.i11.719

79. Maceyka M, Harikumar KB, Milstien S, Spiegel S. Sphingosine-1-phosphate signaling and its role in disease. Trends Cell Biol (2012) 22(1):50-60. doi:10.1016/j.tcb.2011.09.003

80. Assar ME, Angulo J, Rodriguez-Manas L. Diabetes and ageing-induced vascular inflammation. J Physiol (2016) 594(8):2125-46. doi:10.1113/JP270841

81. Heywood SE, Richart AL, Henstridge DC, Alt K, Kiriazis H, Zammit $\mathrm{C}$, et al. High-density lipoprotein delivered after myocardial infarction increases cardiac glucose uptake and function in mice. Sci Transl Med (2017) 9(411):eaam6084. doi:10.1126/scitranslmed.aam6084

82. Ding Y, Sun X, Shan PF. MicroRNAs and cardiovascular disease in diabetes mellitus. Biomed Res Int (2017) 2017:4080364. doi:10.1155/2017/4080364

83. Tian FJ, An LN, Wang GK, Zhu JQ, Li Q, Zhang YY, et al. Elevated microRNA-155 promotes foam cell formation by targeting HBP1 in atherogenesis. Cardiovasc Res (2014) 103(1):100-10. doi:10.1093/cvr/cvu070

84. Moura J, Borsheim E, Carvalho E. The role of microRNAs in diabetic complications-special emphasis on wound healing. Genes (2014) 5(4):926-56. doi:10.3390/genes5040926

85. Elgheznawy A, Shi L, Hu J, Wittig I, Laban H, Pircher J, et al. Dicer cleavage by calpain determines platelet microRNA levels and function in diabetes. Circ Res (2015) 117(2):157-65. doi:10.1161/CIRCRESAHA.117.305784

86. Ritsinger V, Malmberg K, Martensson A, Ryden L, Wedel H, Norhammar A. Intensified insulin-based glycaemic control after myocardial infarction: mortality during 20 year follow-up of the randomised diabetes mellitus insulin glucose infusion in acute myocardial infarction (DIGAMI 1) trial. Lancet Diabetes Endocrinol (2014) 2(8):627-33. doi:10.1016/S2213-8587(14)70088-9

87. Mellbin LG, Malmberg K, Ryden L, Wedel H, Vestberg D, Lind M. The relationship between glycaemic variability and cardiovascular complications in patients with acute myocardial infarction and type 2 diabetes: a report from the DIGAMI 2 trial. Eur Heart J (2013) 34(5):374-9. doi:10.1093/eurheartj/ ehs384

88. Skyler JS, Bergenstal R, Bonow RO, Buse J, Deedwania P, Gale EA, et al. Intensive glycemic control and the prevention of cardiovascular events: implications of the ACCORD, ADVANCE, and VA diabetes trials: a position statement of the American Diabetes Association and a scientific statement of the American College of Cardiology Foundation and the American Heart Association. Diabetes Care (2009) 32(1):187-92. doi:10.2337/dc08-9026

89. Chow EIA, Bernjak A, Ajjan RA, Heller SR. Effect of hypoglycaemia on thrombosis and inflammation in patients with type 2 diabetes. Lancet (2014) 383(Suppl 1):S35. doi:10.1016/S0140-6736(14)60298-1

90. Elwen FR, Huskinson A, Clapham L, Bottomley MJ, Heller SR, James C, et al. An observational study of patient characteristics and mortality following hypoglycemia in the community. BMJ Open Diabetes Res Care (2015) 3(1):e000094. doi:10.1136/bmjdrc-2015-000094
91. Goto A, Arah OA, Goto M, Terauchi Y, Noda M. Severe hypoglycaemia and cardiovascular disease: systematic review and meta-analysis with bias analysis. BMJ (2013) 347:f4533. doi:10.1136/bmj.f4533

92. Zinman B, Wanner C, Lachin JM, Fitchett D, Bluhmki E, Hantel S, et al. Empagliflozin, cardiovascular outcomes, and mortality in type 2 diabetes. $N$ Engl J Med (2015) 373(22):2117-28. doi:10.1056/NEJMoa1504720

93. Marso SP, Daniels GH, Brown-Frandsen K, Kristensen P, Mann JF, Nauck MA, et al. Liraglutide and cardiovascular outcomes in type 2 diabetes. $N$ Engl J Med (2016) 375(4):311-22. doi:10.1056/NEJMoa1607141

94. Neal B, Perkovic V, Mahaffey KW, de Zeeuw D, Fulcher G, Erondu N, et al. Canagliflozin and cardiovascular and renal events in type 2 diabetes. $N$ Engl J Med (2017) 377(7):644-57. doi:10.1056/NEJMoa1611925

95. Poreba M, Mostowik M, Siniarski A, Golebiowska-Wiatrak R, Malinowski KP Haberka M, et al. Treatment with high-dose n-3 PUFAs has no effect on platelet function, coagulation, metabolic status or inflammation in patients with atherosclerosis and type 2 diabetes. Cardiovasc Diabetol (2017) 16(1):50. doi:10.1186/s12933-017-0523-9

96. Rollini F, Franchi F, Muniz-Lozano A, Angiolillo DJ. Platelet function profiles in patients with diabetes mellitus. J Cardiovasc Transl Res (2013) 6(3):329-45. doi:10.1007/s12265-013-9449-0

97. Ferreiro JL, Angiolillo DJ. Diabetes and antiplatelet therapy in acute coronary syndrome. Circulation (2011) 123(7):798-813. doi:10.1161/ CIRCULATIONAHA.109.913376

98. Undas A, Brummel-Ziedins KE, Mann KG. Antithrombotic properties of aspirin and resistance to aspirin: beyond strictly antiplatelet actions. Blood (2007) 109(6):2285-92. doi:10.1182/blood-2006-01-010645

99. Ajjan RA, Standeven KF, Khanbhai M, Phoenix F, Gersh KC, Weisel JW, et al. Effects of aspirin on clot structure and fibrinolysis using a novel in vitro cellular system. Arterioscler Thromb Vasc Biol (2009) 29(5):712-7. doi:10.1161/ ATVBAHA.109.183707

100. Sacco M, Pellegrini F, Roncaglioni MC, Avanzini F, Tognoni G, Nicolucci A, et al. Primary prevention of cardiovascular events with low-dose aspirin and vitamin $\mathrm{E}$ in type 2 diabetic patients: results of the primary prevention project (PPP) trial. Diabetes Care (2003) 26(12):3264-72. doi:10.2337/ diacare.26.12.3264

101. Saito Y, Okada S, Ogawa H, Soejima H, Sakuma M, Nakayama M, et al. Low-dose aspirin for primary prevention of cardiovascular events in patients with type 2 diabetes mellitus: 10-year follow-up of a randomized controlled trial. Circulation (2017) 135(7):659-70. doi:10.1161/ CIRCULATIONAHA.116.025760

102. Belch J, MacCuish A, Campbell I, Cobbe S, Taylor R, Prescott R, et al. The prevention of progression of arterial disease and diabetes (POPADAD) trial: factorial randomised placebo controlled trial of aspirin and antioxidants in patients with diabetes and asymptomatic peripheral arterial disease. BMJ (2008) 337:a1840. doi:10.1136/bmj.a1840

103. Authors/Task Force Members, Ryden L, Grant PJ, Anker SD, Berne C, Cosentino F, et al. ESC guidelines on diabetes, pre-diabetes, and cardiovascular diseases developed in collaboration with the EASD: the Task Force on diabetes, pre-diabetes, and cardiovascular diseases of the European Society of Cardiology (ESC) and developed in collaboration with the European Association for the Study of Diabetes (EASD). Eur Heart J (2013) 34(39):3035-87. doi:10.1093/eurheartj/eht108

104. Vaduganathan M, Alviar CL, Arikan ME, Tellez A, Guthikonda S, DeLao T, et al. Platelet reactivity and response to aspirin in subjects with the metabolic syndrome. Am Heart J (2008) 156(5):1002.e1-7. doi:10.1016/j. ahj.2008.08.002

105. Angiolillo DJ, Badimon JJ, Saucedo JF, Frelinger AL, Michelson AD, Jakubowski JA, et al. A pharmacodynamic comparison of prasugrel vs. highdose clopidogrel in patients with type 2 diabetes mellitus and coronary artery disease: results of the Optimizing anti-Platelet Therapy in diabetes MellitUS (OPTIMUS)-3 trial. Eur Heart J (2011) 32(7):838-46. doi:10.1093/eurheartj/ ehq494

106. Tan Q, Jiang X, Huang S, Zhang T, Chen L, Xie S, et al. The clinical efficacy and safety evaluation of ticagrelor for acute coronary syndrome in general ACS patients and diabetic patients: a systematic review and meta-analysis. PLoS One (2017) 12(5):e0177872. doi:10.1371/journal.pone.0177872

107. Franchi F, Rollini F, Cho JR, King R, Phoenix F, Bhatti M, et al. Effects of dabigatran on the cellular and protein phase of coagulation in patients 
with coronary artery disease on dual antiplatelet therapy with aspirin and clopidogrel. Results from a prospective, randomised, double-blind, placebo-controlled study. Thromb Haemost (2016) 115(3):622-31. doi:10.1160/ TH15-06-0467

108. Versteeg HH, Heemskerk JW, Levi M, Reitsma PH. New fundamentals in hemostasis. PhysiolRev (2013) 93(1):327-58. doi:10.1152/physrev.00016.2011

109. Silvain J, Beygui F, Barthelemy O, Pollack C Jr, Cohen M, Zeymer U, et al. Efficacy and safety of enoxaparin versus unfractionated heparin during percutaneous coronary intervention: systematic review and meta-analysis. BMJ (2012) 344:e553. doi:10.1136/bmj.e553

110. Schiele F. Fondaparinux and acute coronary syndromes: update on the OASIS 5-6 studies. Vasc Health Risk Manag (2010) 6:179-87. doi:10.2147/VHRM. S6099

111. Valgimigli M, Frigoli E, Leonardi S, Rothenbuhler M, Gagnor A, Calabro P, et al. Bivalirudin or unfractionated heparin in acute coronary syndromes. $N$ Engl J Med (2015) 373(11):997-1009. doi:10.1056/NEJMoa1507854

112. Feit F, Manoukian SV, Ebrahimi R, Pollack CV, Ohman EM, Attubato MJ, et al. Safety and efficacy of bivalirudin monotherapy in patients with diabetes mellitus and acute coronary syndromes: a report from the ACUITY (acute catheterization and urgent intervention triage strategy) trial. J Am Coll Cardiol (2008) 51(17):1645-52. doi:10.1016/j.jacc.2007.11.081
113. Eikelboom JW, Connolly SJ, Bosch J, Dagenais GR, Hart RG, Shestakovska O, et al. Rivaroxaban with or without aspirin in stable cardiovascular disease. $N$ Engl J Med (2017) 377(14):1319-30. doi:10.1056/NEJMoa1709118

114. Revenko AS, Gao D, Crosby JR, Bhattacharjee G, Zhao C, May C, et al. Selective depletion of plasma prekallikrein or coagulation factor XII inhibits thrombosis in mice without increased risk of bleeding. Blood (2011) 118(19):5302-11. doi:10.1182/blood-2011-05-355248

115. Fredenburgh JC, Gross PL, Weitz JI. Emerging anticoagulant strategies. Blood (2017) 129(2):147-54. doi:10.1182/blood-2016-09-692996

Conflict of Interest Statement: The authors declare that the research was conducted in the absence of any commercial or financial relationships that could be construed as a potential conflict of interest.

Copyright $\odot 2018$ Pechlivani and Ajjan. This is an open-access article distributed under the terms of the Creative Commons Attribution License (CC BY). The use, distribution or reproduction in other forums is permitted, provided the original author(s) or licensor are credited and that the original publication in this journal is cited, in accordance with accepted academic practice. No use, distribution or reproduction is permitted which does not comply with these terms. 